\title{
A Simple and Fast Method for the Production and Characterization of Methylic and Ethylic Biodiesels from Tucum Oil via an Alkaline Route
}

\author{
Marcelo Firmino de Oliveira, ${ }^{1}$ Andressa Tironi Vieira, ${ }^{2}$ Antônio Carlos Ferreira Batista, ${ }^{3}$ \\ Hugo de Souza Rodrigues, ${ }^{3}$ and Nelson Ramos Stradiotto ${ }^{2}$ \\ ${ }^{1}$ Departamento de Química, Faculdade de Filosofia, Ciências e Letras de Ribeirão Preto, Universidade de São Paulo,
$14040-901$ Ribeirão Preto, SP, Brazil
${ }^{2}$ Departamento de Química Analítica, Instituto de Química, UNESP, 14800-900 Araraquara, SP, Brazil
${ }^{3}$ Laboratório de energias Renováveis e Meio ambiente do Pontal (LERMAP), UFU, 38302-000 Ituiutaba, MG, Brazil \\ Correspondence should be addressed to Marcelo Firmino de Oliveira, marcelex@ffclrp.usp.br
}

Received 31 August 2010; Revised 6 February 2011; Accepted 9 March 2011

Academic Editor: Stanley Brul

Copyright (C) 2011 Marcelo Firmino de Oliveira et al. This is an open access article distributed under the Creative Commons Attribution License, which permits unrestricted use, distribution, and reproduction in any medium, provided the original work is properly cited.

\begin{abstract}
A simple, fast, and complete route for the production of methylic and ethylic biodiesel from tucum oil is described. Aliquots of the oil obtained directly from pressed tucum (pulp and almonds) were treated with potassium methoxide or ethoxide at $40^{\circ} \mathrm{C}$ for $40 \mathrm{~min}$. The biodiesel form was removed from the reactor and washed with $0.1 \mathrm{M} \mathrm{HCl}$ aqueous solution. A simple distillation at $100^{\circ} \mathrm{C}$ was carried out in order to remove water and alcohol species from the biodiesel. The oxidative stability index was obtained for the tucum oil as well as the methylic and ethylic biodiesel at $6.13,2.90$, and $2.80 \mathrm{~h}$, for storage times higher than 8 days. Quality control of the original oil and of the methylic and ethylic biodiesels, such as the amount of glycerin produced during the transesterification process, was accomplished by the TLC, GC-MS, and FT-IR techniques. The results obtained in this study indicate a potential biofuel production by simple treatment of tucum, an important Amazonian fruit.
\end{abstract}

\section{Introduction}

The search for alternative fuels to replace oil-derived energy sources has received increased attention worldwide over the last decades, more specifically since the oil crisis in the 20th century. Fossil fuels constitute a finite energy source, and they emit a large amount of pollutants [1]. Interesting alternatives have been presented as possible substitutes for fossil fuels, such as fuel ethanol [1] and biofuels from animal and plant oils. Nowadays, these oils appear as a promising replacement for diesel oil, and special attention has been devoted to biodiesel [2]. This biofuel consists of monoalkylesthers of long chain fatty acids, derived from plant or animal oils [2]. A schematic diagram for the production of biodiesel from triacylglycerols is shown in Figure 1.
Biodiesel production offers several advantages, since this fuel is renewable and environmentally friendly, can be mixed with diesel, not to mention its numerous animal [3-7] and plant sources [8-14].

Of all the reported sources of plant oils for biodiesel production, tucum (Astrocaryum vulgate Mart) must be highlighted [15]. The fruit of tucum trees is extensively used by Amazonian communities for the production of food and cosmetics [15-17] among other applications.

The oil is commonly extracted from tucum by pressing the entire fruit (pulp and almonds together). Some scientific studies about its use as a biofuel have been reported $[16,17]$. In terms of chemical composition, the tucum oil is rich in betacarotene [16] and contains oleic and palmitic acids as the major fatty acids, apart from a small level of linoleic acid [15]. This oil is considered an important raw material for 


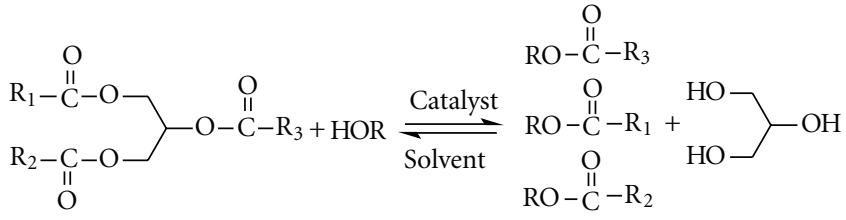

Figure 1: Schematic diagram of triacylglycerol transesterification by alcoholysis, in the presence of catalysts.

the production of oleochemicals, and it is stable to oxidative deterioration.

Despite its interesting advantages from an oleochemical view point, application of tucum oil as a raw material for biodiesel production has not been extensively reported. In this context, Lima et al. [18] studied the production of biodiesel from tucum by transesterification with anhydrous ethanol and methanol, using $\mathrm{NaOH}$ as catalyst. The authors concluded that the properties of the two types of biodiesel (ethanolic and methanolic) were very similar to those of oilderived diesel.

In this context, research on biodiesel production from tucum fruit is justified, once this constitutes an important motivational factor for Amazonian rural communities. In this way, the Amazonian rural population could obtain their own biofuel in a sustainable fashion. Therefore, the aim of this work was to develop a simple, fast and efficient alkaline $(\mathrm{KOH})$ route for the production of methylic and ethylic biodiesels from tucum oil, extracted from Amazonian trees by local communities in a sustainable way, in order to provide a local biofuel production.

\section{Materials and Methods}

2.1. Biodiesel Production. The tucum oil was obtained by pressing the entire fruit (pulp and almonds) in a conventional mechanic press. The obtained oil was filtered through a glass tube of $1 \mathrm{~cm}$ diameter filed with cotton. Potassium methoxide and potassium ethoxide were prepared using potassium hydroxide P.A., and methanol P.A., and ethanol P.A. purchased from Sinth, respectively, following a similar experimental process described in the literature [18]. The methoxide form was obtained after adding $9.5 \mathrm{~g}$ of $\mathrm{KOH}$ at $120 \mathrm{~mL}$ of methanol under stirring until the complete dissolution (exothermic reaction). The ethoxide form also was obtained after adding $9.5 \mathrm{~g}$ of $\mathrm{KOH}$ at $150 \mathrm{~mL}$ of ethanol under stirring until the complete dissolution.

Each aliquot the of oil-alcohol- $\mathrm{KOH}$ mixture (methylic or ethylic form) was kept under stirring at $40^{\circ} \mathrm{C}$ for $40 \mathrm{~min}$. The transesterification process was monitored by thin layer chromatography: the development of separation in hexane/ethyl acetate $95 \% / 5 \%$ solution can exhibit a decrease of oil band and increase of biodiesel bands through the time.

After the decantation step, each biodiesel form was separated from glycerin and washed with $\mathrm{HCl} 0.1 \mathrm{M}$ solution. A simple distillation at $100^{\circ} \mathrm{C}$ was performed, in order to remove both water and alcohol from the biodiesel samples.

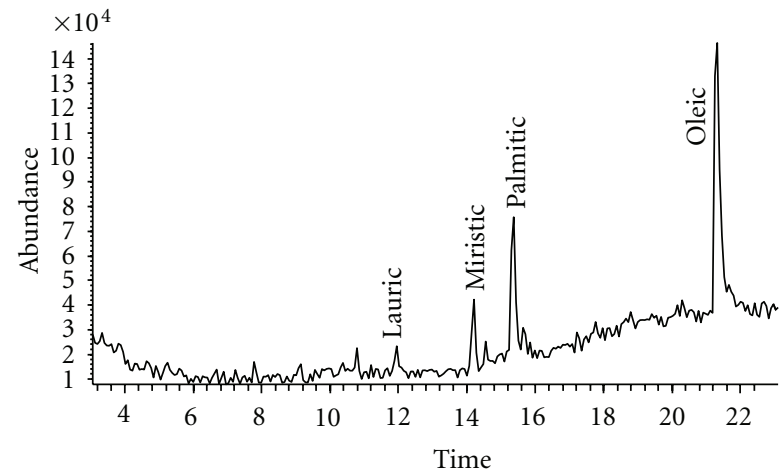

Figure 2: Chromatogram with mass spectrum identification obtained for the free fatty acids of tucum oil-identification of its major oleochemical components.

2.2. Oxidative Stability Studies. The importance of this study consists of finding out up to which time point there is no formation of secondary compounds of oxidation, and to establish when the onset of increasing oxidation rate, peroxide index, oxygen absorption, and formation of volatile substances take place.

The oxidative stability measurements were carried out using a 873 Rancimat equipment from Metrohm. The tucum oil and the methylic and ethylic biodiesel samples were submitted to an air gas flow of $10 \mathrm{~L} / \mathrm{h}$, under a continuous heating at $110^{\circ} \mathrm{C} \pm 0.3^{\circ} \mathrm{C}$.

2.3. GC-MS Analysis. The chromatographic analysis of the biodiesel samples such as the original oil and of the glycerin obtained during the transesterification process was carried out using an HP gas chromatograph, model CG 5890, series II, equipped with an HP1 column (100\% dimethyl polysiloxane) with $30 \mathrm{~m}$ length and $0.2 \mathrm{~mm}$ internal diameter. The mobile phase consisted of $\mathrm{H}_{2}$ and $\mathrm{N}_{2}(30 \mathrm{~L} / \mathrm{min})$ and air $(300 \mathrm{~L} / \mathrm{min})$. An injection volume of $0.5 \mu \mathrm{L}$ was used in all the measurements. An injector temperature of $200^{\circ} \mathrm{C}$ was employed, and analysis was accomplished by using a temperature ramp from 80 to $200^{\circ} \mathrm{C}$. The mass spectra of the main chromatographic peaks monitored in a mass spectrometer HP model 5988A, which was coupled to the chromatograph.

2.4. FT-IR Analysis. The spectroscopic measurements for all the studied species were recorded on an infrared spectrophotometer from Perkin Elmer, model 1430, in the spectral work range from 4500 to $450 \mathrm{~cm}^{-1}$.

\section{Results and Discussion}

The methylic route was more efficient for biodiesel production $(75.1 \%)$ than the ethylic route $(66.7 \%)$. Both results allowed us to propose this methodology as an alternative route for biodiesel production. The presence of Lauric, Miristic, Palmitic, and Oleic fatty acids as the major components of the tucum oil, detected retention times range 


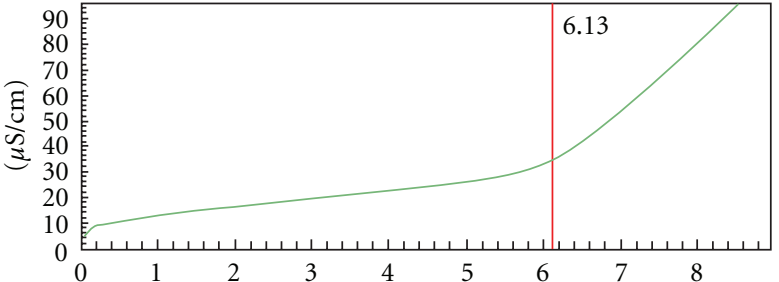

(h)

(a)

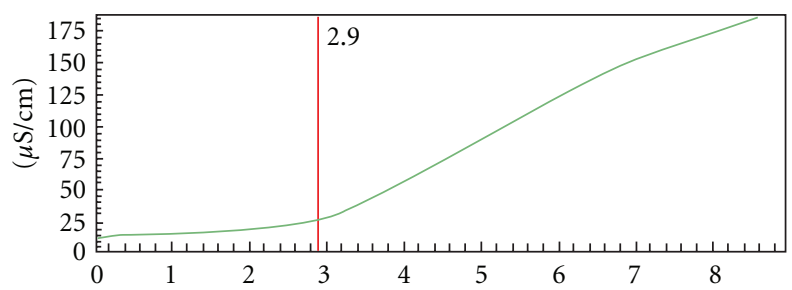

(h)

(b)

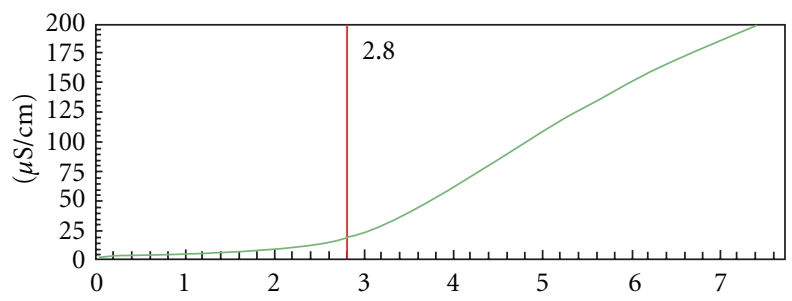

(h)

(c)

FIGURE 3: oxidative stability index measurements for: (a) tucum oil, (b) methylic biodiesel, and (c) ethylic biodiesel.

from 12 to $23 \mathrm{~min}$, was confirmed by GC-MS, as indicated in Figure 2, in good agreement with previous works reported in the literature [15-18].

Biodiesel production was also confirmed by the FT-IR technique. In this case, it is possible to check the location of the bands of the carbonyls of the oils in relation to the ones of the biodiesel. The main difference observed between the infrared spectrum of tucum oil and those of its biodiesels was a small displacement of the $\mathrm{C}=\mathrm{O}$ stretching band of the biodiesel samples to lower energy $\left(1747-1740 \mathrm{~cm}^{-1}\right)$, which can be explained in terms of the substitution of glycerol by the methoxilic radical [18].

The studies of oxidative stability index indicated loss of chemical stability for the biodiesels in relation to the original oil, as indicated in Figure 3. The results about stability index and storage time are reported in Table 1 . While it was possible to observe a stability time of $6.13 \mathrm{~h}$ for the oil samples, only $2.90 \mathrm{~h}$ and $2.80 \mathrm{~h}$ were observed for the methylic and ethylic biodiesels. According to Brazilian laws, for example [19], the indexes obtained for biodiesels in this work are under the recommended values $\left(6 \mathrm{~h}\right.$ at $\left.110^{\circ} \mathrm{C}\right)$. The oil form is more stable because it is rich in carotenoids.

The storage time differs from the oxidative stability index values once no induced oxidation was provided or
TABLE 1: Oxidative stability index and storage time studies obtained for the tucum oil and the methylic and ethylic biodiesels.

\begin{tabular}{lcc}
\hline Sample & $\begin{array}{c}\text { Oxidative stability index } \\
(\mathrm{h})\end{array}$ & $\begin{array}{c}\text { Storage time at } 20^{\circ} \mathrm{C} \\
(\text { days })\end{array}$ \\
\hline Tucum oil & 6.13 & 35.2 \\
Methylic biodiesel & 2.90 & 9.52 \\
Ethylic biodiesel & 2.80 & 8.73 \\
\hline
\end{tabular}

accelerated. It consists in the storage time at $20^{\circ} \mathrm{C}$. In this case, it was possible to observe a storage time of 35 days for the tucum oil, which is possible due to the presence of water and the high acidity of the sample.

\section{Conclusions}

The proposed methodology successfully produced methylic and ethylic biodiesel from the tucum oil using $\mathrm{KOH}$ as reagent for alkoxide production. In spite of being used in several ways by local Amazonian communities, the tucum oil can also be converted into its biodiesel form, consisting of an interesting self-production route for biofuel and thus contributing to sustainable exploitation of this species. The oxidative stability indexes and storage time make this oil a good precursor for local biodiesel production, even though further studies are needed to establish its application in diesel engines, for example.

\section{Acknowledgment}

The authors thank the financial support of CAPES, CNPq, FINEP, and FAPEMIG.

\section{References}

[1] M. F. de Oliveira, A. A. Saczk, L. L. Okumura, and N. R. Stradiotto, "Analytical methods employed at quality control of fuel ethanol," Energy and Fuels, vol. 23, no. 10, pp. 4852-4859, 2009.

[2] F. C. C. Oliveira, P. A. Z. Suarez, and W. L. P. Santos, "Biodiesel: possibilidades e desafios," Quimica Nova na Escola, vol. 28, pp. 3-8, 2008.

[3] O. Andersen and J. E. Weinbach, "Residual animal fat and fish for biodiesel production. Potentials in Norway," Biomass and Bioenergy, 2010.

[4] Y. Liang, N. Sarkany, Y. Cui, and J. W. Blackburn, "Batch stage study of lipid production from crude glycerol derived from yellow grease or animal fats through microalgal fermentation," Bioresource Technology, vol. 101, no. 17, pp. 6745-6750, 2010.

[5] C. L. Bianchi, D. C. Boffito, C. Pirola, and V. Ragaini, "Low temperature de-acidification process of animal fat as a pre-step to biodiesel production," Catalysis Letters, vol. 134, no. 1-2, pp. 179-183, 2010.

[6] I. Rivera, G. Villanueva, and G. Sandoval, "Producción de biodiesel a partir de residuos grasos animales por vía enzimática," Grasas y Aceites, vol. 60, no. 5, pp. 468-474, 2009.

[7] C. Öner and Ş. Altun, "Biodiesel production from inedible animal tallow and an experimental investigation of its use as alternative fuel in a direct injection diesel engine," Applied Energy, vol. 86, no. 10, pp. 2114-2120, 2009. 
[8] N. C. Om Tapanes, D. A. Gomes Aranda, J. W. de Mesquita Carneiro, and O. A. Ceva Antunes, "Transesterification of Jatropha curcas oil glycerides: theoretical and experimental studies of biodiesel reaction," Fuel, vol. 87, no. 10-11, pp. 2286-2295, 2008.

[9] C. da Silva, F. de Castillos, J. V. Oliveira, and L. C. Filho, "Continuous production of soybean biodiesel with compressed ethanol in a microtube reactor," Fuel Processing Technology, vol. 91, pp. 1274-1281, 2010.

[10] H. Joshi, B. R. Moser, S. N. Shah, A. Mandalika, and T. Walker, "Improvement of fuel properties of cottonseed oil methyl esters with commercial additives," European Journal of Lipid Science and Technology, vol. 112, no. 7, pp. 802-809, 2010.

[11] J. A. Melero, L. F. Bautista, G. Morales, J. Iglesias, and R. Sánchez-Vázquez, "Biodiesel production from crude palm oil using sulfonic acid-modified mesostructured catalysts," Chemical Engineering Journal, vol. 161, no. 3, pp. 323-331, 2010.

[12] J. Zhang, S. Chen, R. Yang, and Y. Yan, "Biodiesel production from vegetable oil using heterogenous acid and alkali catalyst," Fuel, vol. 89, pp. 2939-2944, 2010.

[13] M. Peri and L. Baldi, "Vegetable oil market and biofuel policy: an asymmetric cointegration approach," Energy Economics, vol. 32, no. 3, pp. 687-693, 2010.

[14] A. Demirbas, "New biorenewable fuels from vegetable oils," Energy Sources Part A, vol. 32, no. 7, pp. 628-636, 2010.

[15] F. O. J. Oboh, "The oleochemical potential of tucum (Astrocaryum vulgare Mart) pulp oil and stearin," Rivista Italiana delle Sostanze Grasse, vol. 86, no. 1, pp. 39-47, 2009.

[16] D. B. Rodriguez-Amaya, J. Amaya-Farfan, and M. Kimura, "Carotenoid composition of Brazilian fruits and vegetables," Acta Horticulturae, vol. 744, pp. 409-416, 2007.

[17] F. O. J. Oboh and R. A. Oderinde, "Analysis of the pulp and pulp oil of the tucum (Astrocaryum vulgare Mart) fruit," Food Chemistry, vol. 30, no. 4, pp. 277-287, 1988.

[18] J. R. D. O. Lima, R. B. da Silva, E. Miranda de Moura, and C. V. Rodarte de Moura, "Biodiesel of tucum oil, synthesized by methanolic and ethanolic routes," Fuel, vol. 87, no. 8-9, pp. 1718-1723, 2008.

[19] EN 14112:2003, "Fat and Oil Derivatives_Fatty Acid Methyl Esters (FAME)," Determination of oxidation stability (accelerated oxidation test), 2003. 

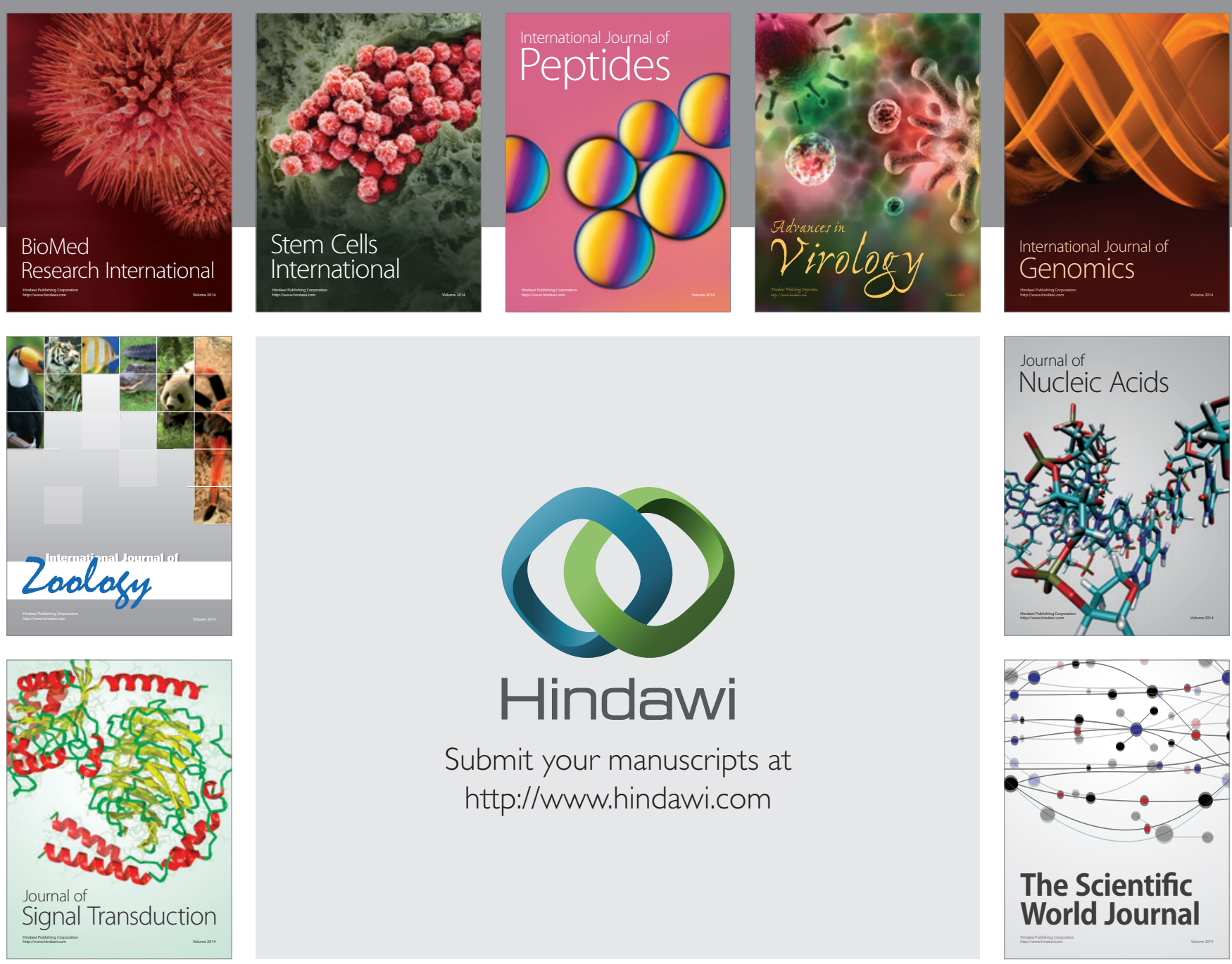

Submit your manuscripts at

http://www.hindawi.com
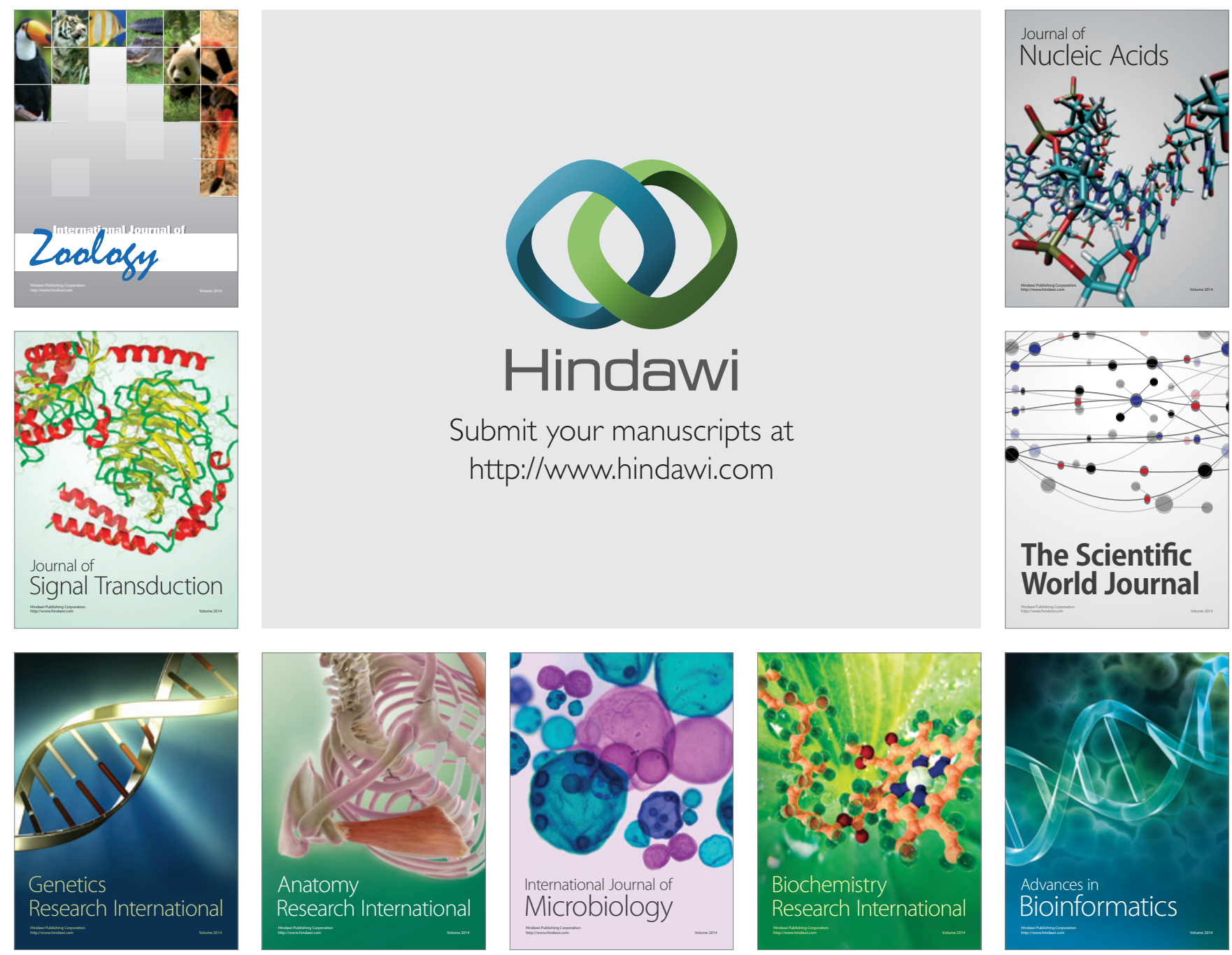

The Scientific World Journal
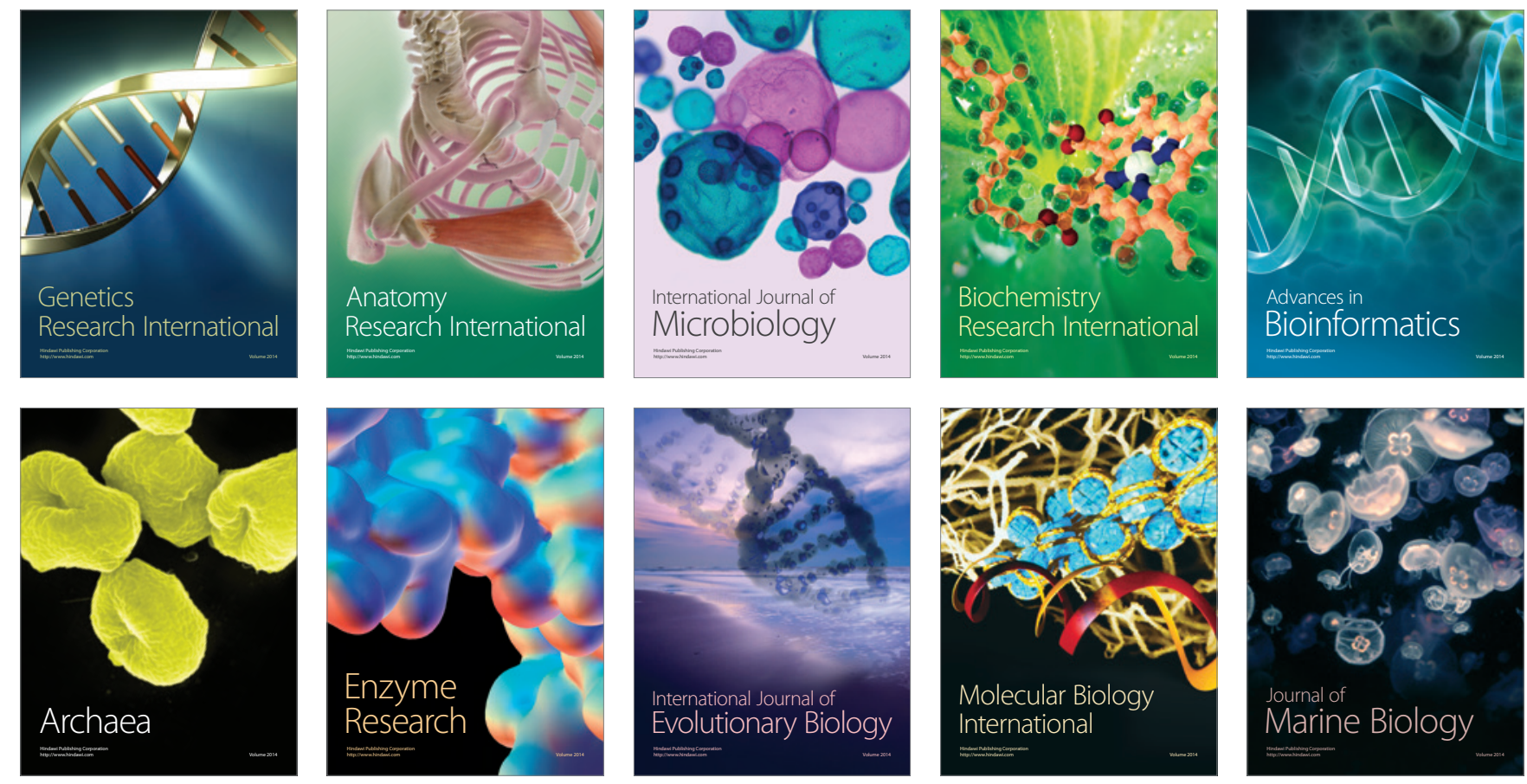